this country are well known to all those interested, or secondly, that no practical action could be taken which is not already being taken, even if a public demand should be created.

With regard to the first of these objections it may be interesting to note that, although all the members of the Joint Committee on Venereal Disease were experienced and knowledgeable workers in this field, many of the facts presented to us by the representatives of the Metropolitan Police and the Home Office were new to us. As regards the second objection, whilst we found the legal and administrative problems presented by prostitution even more complicated than we had supposed, yet we felt that certain measures which would not in the present state of public ignorance be tolerated by Parliament or the electorate would be likely to win support if all the facts were known, and that an important advance would be possible not only, or perhaps chiefly, by means of legal enactments, but by public support for the implementation of existing powers and public condemnation of practices now tolerated through ignorance or indifference.

I wish I could say more on this important and difficult subject, but I wish even more that I were in a position to give the full facts, free from emotion or prejudice, scientifically-but mercilessly.

\title{
DISCUSSION ON THE PRECEDING PAPER
}

DR. G. L. M. McEluigott (the President) said that Sir Weldon had given them a most interesting address. The most impressive result of sulphonamide treatment was the great decrease in the number of complicated cases of gonorrhœa. A careful survey, carried out at St. Mary's Hospital at the end of the first year of sulphonamide therapy, had shown that the incidence of complications of gonorrhoea, in both men and women, was only about one eighth of what it had formerly been.

With regard to oral penicillin tablets, he saw that such tablets were now on the market. One great danger was that they might not be taken as directed, and that if they became as easy to obtain as the sulphonamides had become there was a danger that syphilis might be masked.

He did not agree with the suggestion that nonvenereal cases should invariably be referred to other departments of the hospital, which often did not have the facilities for dealing with these conditions. In most hospitals the best place for treating trichomonas infestation was undoubtedly the venereal diseases department. Another point was that the tests for the exclusion of gonorrhoea in women would often take as long as the curing of the original complaint.

MR. A. J. KING said that he was particularly glad that Sir Weldon had stressed the importance of telling the public the whole truth and nothing but the truth.

Inevitably there must be a divergence of viewpoint between the public health expert and the clinician. The public health expert was apt to take the attitude that one only had to find the patients-to shepherd the sheep into the fold, so to speak - and 100 per cent. cure was certain and the problem was solved. A great deal of money had been spent on propaganda which would have been better spent in promoting the study of the fundamental pathology of these diseases, of which a great deal was still unknown. Even careful and conscientious treatment left a proportion of cases with latent infectious disease. This applied particularly to the group of diseases which are called primary "non-specific" infections. These were communicable and gave rise to serious complications. They were, moreover, recurring diseases which, on the whole, were not very susceptible to treatment.

Which diseases were to be included among the venereal diseases? The problem was a very much greater one than the official pronouncements on the subject suggested, and the proposal that those patients who were not suffering from syphilis, gonorrhœa, or chancroid, should be turned over to other departments of a hospital was not a practical one. The other departments of the hospital would wish to have nothing to do with them, and if such a course were attempted it would result in extraordinary confusion, and the patients would be the sufferers. With regard to the methods of compulsion which were being advocated, was it not a fact that for the most part the only patients who refused examination and treatment when told that they were probably infected were the dull and backward, the mentally defective, and the psychopathic? When these patients were brought for treatment it often happened that they stayed for a day or two and then disappeared. Nothing could be done about such patients unless they could be detained in proper institutions. Just to get them into hospital was quite ineffective ; they had to be kept in, and there was no provision for that in 33B.

Most would probably agree that the parents of infected children should be compelled, at the least, to see that their children were brought regularly for treatment. Again, those parents who were difficult in this matter were usually of the defective type, and it was not easy to deal with them. There was a case for having some regulation whereby such 
children could be taken away from their parents and put in appropriate institutions if necessity arose.

DR. Forgan said Sir Weldon had mentioned that his Committee's discussions had taken place in a rather emotional atmosphere ; but, in spite of that, the memhers had co-operated well. Their own Society had been founded in a highly emotional atmosphere and such a discussion as they were having that afternoon would have been, in those early days, ultra vires. The fact that they were discussing this subject today was a sign that some progress had been made during the last twenty-five years.

Sir Weldon doubtless knew that he was speaking to the converted, for the Society had unanimously passed a resolution in favour of measures of further control. It was to be hoped that Sir Weldon was right in his view that the introduction of the new National Health Service was going to make easier the control of venereal diseases. His Committee in its recommendations did not exclude for ever the possibility of arming local authorities with powers to be used in the rare cases where the exercise of such powers would be in the public interest. Progress towards the control of these diseases was very slow. They ought to ask themselves as individual citizens of what there was to be afraid. Politicians were more afraid than anyone else. He did not think it mattered what political complexion the Government bore ; no Government was prepared to grasp this nettle.

Col. L. W. Harrison said he agreed with the two measures of compulsion recommended by Sir Weldon's Committee viz. that parents of infected children should be treated, and that parents and guardians of children with congenital syphilis should be compelled to take their charges for treatment. But the older he grew the more opposed he was to any general measure of compulsion. We had been bidden ad nauseam to follow the example of compulsionist countries such as Sweden and Denmark, but how had these fared during the war? In his view, no better than Great Britain. He quoted figures which showed that in Sweden the number of new cases of syphilis had been more than twice as many in 1944 as in any of the immediately pre-war years. In Denmark in 1940 there had been 498 new cases of syphilis, but in 1944 the number was 2,225; thus compulsory laws reinforced by the iron discipline of the Nazis had not. prevailed against war conditions.

The routine testing of pregnant women had been practised a great deal in this country long before the late war.

Concerning incidence in this country, he himself had been interested to note that the increase in England and Wales seemed to have occurred more in the ports than in the inland towns. Comparing seven ports and seven inland towns, each group having approximately the same population of about three million, the number of male cases of early syphilis in the period 1939 to 1944 was 7,901 in the ports and 2,835 in the inland towns. Of female cases of early syphilis in the same period, there had been about twice as many $(4,100)$ in the ports as in the inland towns $(2,064)$; there had not been a corresponding increase in congenital syphilis in children under one year of age.

He thought that penicillin tablets were a public danger owing to the risk of under-dosage which their indiscriminate use by the general public without medical guidance would entail.

With regard to Regulation 33B, this was introduced for the protection of the Armed Forces, and he did not think it would be much used in civilian work.

He thought that more attention should be concentrated on persuading the original patient to bring his or her contact for treatment; it was a far cheaper method of contact-tracing than visiting by social workers.

DR. McLaChLan suggested that, while a large number of clinics in this country had reasonable schemes of treatment, this was by no means universal. Itinerant patients often got different instructions at different clinics : this was particularly noticeable among seafarers treated partly in this country and partly in foreign ports.

The Society might usefully sponsor various schemes of treatment which would be regarded as " standard." The efficacy of the present schemes of treatment could only be assessed on the end-results of a sufficient number of cases, and this could best be done by some central body such as their Society.

Dr. Douglas Campbell referred to standard courses of treatment as given in the Army. Although these were sometimes resented by other venereologists requested to continue the treatment, in many cases the results were good. It might be worth while, speaking internationally, if an agreement could be reached whereby a patient who had started treatment in one place could be assured of the continuation of the same treatment when he moved elsewhere. He thought that the clinician who first saw the patient should have a certain right of suggesting the treatment to be followed by other clinicians. The question of control, especially in the case of children, should be pressed. At the moment there was a very good health service for school-children, but there was no power to bring a child up for treatment, and often they had to rely on the help of purely voluntary bodies, such as the National Society for the Prevention of Cruelty to Children, in order to get these children to the clinics for the necessary treatment.

On the controversial matter of prostitution, his experience had been mainly in provincial towns where no great number of infections were forthcoming from the frank prostitute. Abroad, of course, the prostitute was a very great danger. Only in one town did he see the control of prostitution do good, and that was Algiers, a town in which there was no casual promiscuity. The troops could be exposed only in brothels, and the brothels in that town were relatively well looked after. 
DR. MACFarLane thought that government propaganda had little or no influence on infected individuals who belong to that section of the community which constitutes the most fruitful source of venereal infection in the country. The value of paper propaganda would appear to be restricted in the main to those who run the risk of acquiring disease but who eventually are classified as non-venereal.

While he could not support compulsory treatment for all types of venereal diseases, the pregnant woman suffering from syphilis should be compelled to attend for treatment, assuming that no valid excuse could be given by the individual and that reasonable social efforts had been made to persuade the patient to co-operate.

Squadron Leader Hobbs said that he was in Germany recently and he found that since treatment by penicillin had been available there was a relative increase of syphilis in proportion to gonorrhœa.

The PRESIDENT remarked that from a preliminary scrutiny of the figures for 1946 the syphilis ratio did appear to be getting smaller.

DR. Curtis said that it was the experience in Germany and Denmark that the increase of syphilis in the war years was in proportion far greater than the increase in gonorrhœa. In Germany during 1946 the ratio of syphilis to gonorrhœa was about 1 to 3 or 2.5 in the civilian population. He agreed with what Sir Weldon had said, that the health visitor was to be preferred to the ad hoc venereal diseases visitor. He would go further and say that this applied also to the tracing of defaulters. The venereal disease almoner soon became known in the areas where she worked, and such was the urge to conceal the fact of venereal disease that there was a danger that the work of the ad hoc social service worker might result in less good than that of the all-purpose health visitor.

DR. W. N. Mascall said that he had always been a strong advocate for the routine Wassermann test in all pregnant women, and he believed that it should form part of the routine ante-natal supervision. He remembered when the London County Council decided to discontinue their routine testing. This action was partly due to the result of a survey on congenital syphilis, in which it was shown that the number of positive Wassermann reactions found in women attending antenatal clinics was small, and partly due to the fact that the necessary laboratory facilities were not available. Before large-scale examinations could be carried out more specially trained pathologists would be required, and possibly some standardization of the tests would be advisable if reliable results were to be obtained. The difficulties might be overcome by the setting up of central laboratories in some areas.

The results of blood tests as seen on the transfer books of patients from all over the country were most confusing. Half the notations could not be understood, and the results, tabulated perhaps at weekly intervals, varied so considerably that no reliable deductions could be made from them.

He wondered whether sufficient time had yet elapsed to draw any definite conclusions about the end results of treatment with penicillin. There was an incredible disparity in the dosage employed in various clinics, which added considerably to the difficulty in assessing the real value of this therapeutic reagent.

Dr. Heywood said that on the question of standardized treatment the Ministry had already made one recommendation on those lines. What was really needed was a standardization of followup after penicillin therapy. Col. Harrison's comparison of venereal disease figures of Scandinavian countries with those of this country was not a valid argument against compulsory measures. In the case of Sweden, where the increase was not so great as in this country, it had been necessary during the war to maintain a large standing army and navy, which, though subject to military discipline, came outside the scope of the compulsory civilian measures. So far as Denmark was concerned, the manifold increase in syphilis, which up to the outbreak of war had become a rarity; could hardly be attributed to a failure of compulsory methods, since the whole of the Danish Police Force had been in German concentration camps from 1942 onwards.

He thought that Regulation 33B had become essential and that it needed strengthening, especially in compelling syphilitic children to attend for treatment, and also with regard to expectant syphilitic mothers. But before they applied for further compulsory powers he thought they must set their house in order and obtain a uniform standard of diagnosis and treatment. They must have a better laboratory service than they had at present.

DR. R. M. WARREN said that he had been asked to address various sections of the community on this subject, the audiences being Service men, Red Cross and St. John workers, Factory workers, and boys' clubs. They had received very eagerly any information he could give them. He suggested that propaganda must be continuous and not in the form of spasmodic campaigns.

An essential prerequisite of any measures to improve case finding and holding was an improvement in the facilities for diagnosis and treatment. Surely, now that the National Health Service was on the threshold, the opportunity might be taken to bring the venereal disease service throughout the country up to the level of the best now obtaining. Certain minimal standards should be laid down as to equipment and staff, treatment, and follow up.

DR. AtLas said that he himself had been educated on the Continent, and when he came to Great Britain he was amazed at the attitude towards venereal disease and to venereology as a speciality, which was treated like a Cinderella in the reaim of medicine. Compulsory treatment of venereal 
diseases certainly gave good results. The statistical figures given by Col. Harrison for the - Scandinavian countries, particularly the small numbers of syphilis cases before the war, proved the point. In the British Army the treatment of venereal diseases was very well organized, and there always was a certain degree of compulsion towards treatment. The results of treatment in the Army had been very good and the percentage of people who could slip through without any treatment had been small. In this country at present most of the treatment was done in out-patient departments and there was great difficulty in getting patients admitted to hospitals. If patients could only be treated in hospital, and if every venereal disease clinic could have wards with beds attached, it would be a great advantage. It was à matter for the health authorities to provide beds.

DR. D. 1. WILlJams, on the question of penicillin for treating venereal disease, said that one could up to a point draw a parallel with sulphonamide tablets. Patients would always prefer tablets to injections, and he supposed that penicillin tablets would not always be given at three-hourly intervals. One of the dangers was that patients might use the Grug privately and get resistant strains of the organism and perhaps disguise their syphilis.

He suggested a proper research unit in venereal disease.

Sir Weldon Dalrymple-Champneys, in reply, thanked the members for the information they had given him that afternoon. A number of interesting points had been raised. One point on which he had been rather criticised was his suggestion that the venereal disease clinic was being somewhat overwhelmed by non-venereal cases and that sooner than discourage patients from coming it would be better to distribute them to other departments of the hospitals. By this he did not mean that in the present circumstances it would be a good thing that these patients should be sent automatically to the other departments. What he meant was that, as the service developed and as the co-ordination of the Health Service proceeded, there might be a certain number of cases which in time could be referred to other departments. These departments by then would have been staffed and equipped for dealing with such cases. But apparently the members of the Society appeared to be anxious to stick to these cases, and he hoped they would, because he was sure they would deal with them much more efficiently than anybody else.

He had thought that venereal diseases were diseases which were or might be contracted in the act of sexual intercourse. One of the things he had learnt that afternoon was the importance of further research into what might be called " minor" venereal diseases. It was their job in his service to try to provide the necessary mechanism which would bring them into the field, along with the facilities to enable experts to deal with them when they got there. The part of medical administration was not to treat the patients but to help other people to obtain the facilities for such treatment.

He quite agreed with all that had been said about the difficulty of keeping patients under treatment, and obviously unless there was some degree of compulsion this could not be done. These mentally defective and anti-social patients were a great difficulty. He was not against compulsion, but doubted only whether at the present moment compulsion would work or give them more than they would lose. The whole question of the effectiveness and the need of compulsion depended very much on the state of public education and the public attitude. Such attitude changed very rapidly. The history of venereal disease publicity showed the extraordinary pace at which the public outlook had changed.

A very important point was about the need of getting some uniformity in treatment. There was also need for uniformity in nomenclature. He understood and sympathized with those who dreaded too much standardization. This was a thing to guard against, particularly at the present time. He thought there was considerable danger that if they were not careful they would all get into one stamp and one mould. Nevertheless, there was a modicum of standardization without which nothing could be achieved at all. They ought all to agree, whatever their particular speciality was, to arrive at some sort of uniformity at any rate in the recording of the cases.

Some speakers appeared to think that he was claiming more for Regulation 33B than he was. It was a war-time measure and was necessary from that point of view, but he never imagined for a moment that it would cover the whole field or present a permanent solution of the problem.

With regard to the dangers of prostitution, he agreed that in the provinces the problem was not the same as in London, where conditions were very different. But while he agreed that prostitution was a very important channel for conveyance of venereal disease, and one which ought not to be tolerated in any self-respecting city to the extent and under the conditions in which it was tolerated, he felt that measures of control were extremely difficult.

He was interested in what had been said about the venereal disease almoners becoming well known, and, of course, the smaller the neighbourhood, the better known they became. He believed that the co-ordination of work under the new National Service might become a very valuable means of making the venereal disease services more easily available, better housed, better equipped, and better served in every way. The intention was that all services should be co-ordinated for the public good. From the venereal disease clinic point of view he would have thought that any plans for the future were likely to bring advantages. His experience was that the venereal disease department was often very badly housed in the hospital.

In speaking of routine Wassermann tests he did put in a proviso that there must be efficient laboratory services. If they were suddenly to introduce tomorrow Wassermann testing of all pregnant women there would not be the laboratory services available to carry it out, but there was every intention of providing such services to do this. 